\title{
Effects of silenced PAR-2 on cell proliferation, invasion and metastasis of esophageal cancer
}

\author{
JINMEI CHEN, LIQUN XIE, YANMIN ZHENG and CAIHONG LIU \\ Department of Gastroenterology, Affiliated Hospital of Logistics University of People's Armed Police Force, \\ Tianjin 300162, P.R. China
}

Received October 27, 2015; Accepted April 13, 2017

DOI: $10.3892 / \mathrm{ol} .2017 .6711$

\begin{abstract}
The present study aimed to investigate the effect of protease-activated receptor 2 (PAR-2) on cell proliferation, invasion and metastasis in the esophageal EC109 cell line. Two short hairpin RNA (shRNA) expression plasmids were constructed based on the PAR-2 mRNA sequence in humans, and they were transfected into the EC109 esophageal cancer cell line, and the stable interference cell line (shRNA-PAR-2 EC109) was obtained by puromycin selection. Following transfection of PAR-2 shRNA-1, PAR-2 expression was significantly downregulated in mRNA level and protein level in EC109 cells $(\mathrm{P}<0.05)$. The proliferation of EC109 cells transfected with PAR-2 shRNA was significantly lower than the negative control group $(\mathrm{P}<0.05)$. At 24,48 and $72 \mathrm{~h}$, the ratio of proliferation inhibition was $15.92,24.89$ and $32.28 \%$, respectively. Compared with the control group, S-phase arrest was observed in cells transfected with shRNA-PAR-2. The ratio of cells in the $\mathrm{S}$ phase was $32.79 \pm 4.06,26.54 \pm 1.37$ and $33.45 \pm 2.46 \%$ at 24,48 and $72 \mathrm{~h}$, respectively. For invasion, the number of invasive cells was significantly lower in shRNA-PAR2-2 cells compared with the control group $(\mathrm{P}<0.05)$. For metastasis assay, the number of invasive cells was significantly lower in shRNA-PAR2-2 cells compared with the control group $(\mathrm{P}<0.01)$. In the present study, the PAR-2 shRNA plasmid was constructed successfully, which can significantly downregulate PAR-2 expression in EC109 cells. Subsequent to silencing of PAR-2, the proliferation of EC109 cells was inhibited and the capabilities of invasion and migration were reduced. It is indicated that PAR-2 may be a potential target in esophageal cancer.
\end{abstract}

Correspondence to: Dr Jinmei Chen, Department of Gastroenterology, Affiliated Hospital of Logistics University of People's Armed Police Force, 220 Chenglin Road, Hedong, Tianjin 300162, P.R. China

E-mail: sunlight0375@126.com

Key words: protease-activated receptor-2, gene silencing, cell proliferation, invasion, esophageal cancer

\section{Introduction}

Esophageal cancer is one of most common malignant tumors in the clinic. The incidence of esophageal cancer is the 8th highest in malignant tumors and the mortality rate ranks the 6th highest worldwide (1). In China, the morbidity of esophageal cancer, particularly esophageal squamous cell carcinoma, is very high (2). In the early stage no specific clinical manifestations in patients of esophageal cancer are evident (3). Approximately $80 \%$ patients are in advanced or late stage when diagnosed, and the majority of patients cannot be treated with surgery (4). Invasion and metastasis of esophageal cancer in patients is an important factor affecting treatment efficacy and induced poor prognosis (4). It is important to investigate the molecular mechanisms of proliferation-, invasion- and metastasis-associated genes in esophageal cancer, which may provide evidence to prevent and cure esophageal cancer.

Protease activated receptor-2 (PAR-2) is one type of receptor on the cell surface of numerous cells and it belongs to the superfamily of $\mathrm{G}$ protein-coupled protease-activated phase receptor (5). Trypsin, tryptase and coagulation factors are the natural agonists for PAR-2, and activated PAR-2 is involved in a series of biological behaviors, including cell proliferation, invasion and metastasis in tumors $(6,7)$. Our previous study found that PAR-2 performed important roles in growth, invasion and metastasis of the esophageal cancer EC109 cell line (8). The present study aimed to investigate whether PAR-2 effects cell characteristics of EC109 through RNA interference technology. A PAR-2 targeted short hairpin RNA (shRNA) vector was constructed and transfected into the EC109 cell line. The silencing effect of PAR-2 shRNA on its target gene was then observed.

\section{Materials and methods}

Cell line and plasmid. The esophageal cancer EC109 cell line, E. coli top 10 strain and pGFP-V-RS plasmid were provided by the Department of Cell Biology in Logistics University of People's Armed Police Force (Tianjin, China). The DH5 $\alpha$ competent cell was bought from Transgene Biotech Co., Ltd. (Beijing, China).

Construction of vector. The sequence of human PAR-2 mRNA (gene ID, 55065) was retrieved from the GeneBank database 
(https://www.ncbi.nlm.nih.gov/gene/55065). Subsequent to selecting a suitable target site, two oligonucleotide sequences were synthesized: Sequence 1, 5'-TTCCTAACTCTGGCC TTGGTGTTGGCAAT-3'; sequence 2, 5'-GTGTTCTCA TATGTGAAGGTGGCTGCAAG-3', while another one non-specific sequence (5'-GCCTGTTGTACCTCTAATGTC ACTTTCCT-3') was synthesized, all of these sequences were supplied by OriGene Technologies, Inc. (Rockville, MD, USA). The shRNA stem-loop structure was TCAAGAG, and restriction sites of BamHI and HindIII were introduced at the $5^{\prime}$ and 3 ' ends, respectively. The sequences were then connected to the pGFP-V-RS plasmid vector. The recombinant plasmids were transformed to DH5 $\alpha$ competent cells. Briefly, the competent cells $(100 \mu \mathrm{l})$ were incubated with pGFP-V-RS plasmid vector $(5 \mu \mathrm{l})$ on ice for $30 \mathrm{~min}$, followed by $42^{\circ} \mathrm{C}$ for $45 \mathrm{~s}$ and ice bathed for $2 \mathrm{~min}$. Subsequently, $500 \mu \mathrm{l} \mathrm{SOC}$ medium (Zhongaobio Company, Tianjin, China) was added and mixed. The mixture was centrifuged at $37^{\circ} \mathrm{C}$ and $40 \mathrm{xg}$ for $1 \mathrm{~h}$. The product then was transferred to a Kana resistant (30 $\mu \mathrm{g} / \mathrm{ml})$ preloaded lysogeny broth (LB) medium plate and incubated overnight at $37^{\circ} \mathrm{C}$. Three monoclonal colonies were selected on each dish and were inoculated with $3 \mathrm{ml}$ of Kana resistant (final concentration $30 \mu \mathrm{g} / \mathrm{ml}$ ) LB medium (Zhongaobio Company) at $37^{\circ} \mathrm{C}$ overnight. The plasmid DNA was extracted according the manufacturer's instructions (Transgene company, Beijing, China). Plasmid DNA was quantificated. Briefly, $2 \mu \mathrm{l}$ of plasmid DNA and $98 \mu \mathrm{l}$ of TE buffer (Tianjin Chemical Reagent Factory, Tianjin, China) were mixed. A nucleic acid quantifier (GeneQuant 80-2114-98, Cambridge, UK) was used to determine the concentration and record the absorbance ratio at 260 and $280 \mathrm{~nm}$ to assess the purity. Subsequent to detecting the concentration and purity, the plasmids were termed PAR-2 shRNA-1, PAR-2 shRNA-2 and non-specific sequences. The positive bacterium solution was sent to Shanghai Shangon Co., Ltd. (Shanghai, China) for identification by sequence technology.

Cell culture and transfection. EC109 cells were cultured with RPMI-1640 medium (Gibco; Thermo Fisher Scientific, Inc., Waltham, MA, USA) containing $10 \%$ fetal bovine serum (FBS; Minhai Biotech, Beijing, China) in a $5 \% \mathrm{CO}_{2}$ incubator at $37^{\circ} \mathrm{C}$, and $\mathrm{EC} 109$ cells were digested with trypsin for passage following growth $80-90 \%$. PAR-2 shRNA-1, PAR-2 shRNA-2 and non-specific sequences were transfected into cells in the logarithmic growth phase. Briefly, EC109 cells at logarithm phase were digested by trypsin and seeded into six-well plate $\left(5 \times 10^{4}\right.$ per well). The cells were transfected when the growth reached $80 \%$ confluence. The cells and the transfected plasmids were incubated at $37^{\circ} \mathrm{C}$ for $24 \mathrm{~h}$ in the incubator. The blank control of EC109 cells received no transfection. The pGFP-V-RS plasmid with green fluorescent protein was observed using a Microscope Digital Camera DP27 (Olympus, Tokyo, Japan). The transfection efficiency was calculated based on the expression of green fluorescent protein (GFP) at $24 \mathrm{~h}$ post-transfection. The stably transfected cells were selected using $1.0 \mathrm{mg} / \mathrm{ml}$ puromycin by several passages. The EC109 cells without transfection were regarded as the blank control group. Other groups were named based on the transfection: PAR-2 shRNA-1 group; PAR-2 shRNA-2 group; and non-specific sequence group.
Reverse transcription-polymerase chain reaction (RT-PCR). Total RNA from cells at logarithm phase was isolated in each group using TRIzol reagent (Invitrogen; Thermo Fisher Scientific, Inc.), according to the manufacturer's protocol. The cDNA was synthesized from total RNA by reverse transcription with a Reverse Transcription System (Biometra UNO II Thermoblock; Biometra GmbH, Göttingen, German) and stored at $-20^{\circ} \mathrm{C}$. The reverse transcription conditions were $30^{\circ} \mathrm{C}$ for $10 \mathrm{~min}, 42^{\circ} \mathrm{C}$ for $30 \mathrm{~min}, 99^{\circ} \mathrm{C}$ for $5 \mathrm{~min}$ and $5^{\circ} \mathrm{C}$ for $5 \mathrm{~min}$. The primers of PAR- 2 and internal reference $\beta$-actin were designed by Omiga 2.0 software (Accelrys, San Diego, CA, USA) as follows: PAR-2 forward, 5'-AGAAGCCTTATTGGT AAGGTT-3' and reverse, 5'-AACATCATGACAGGTCGT GAT-3', with amplification length $582 \mathrm{bp}$; and $\beta$-actin forward, 5'-TGTTTGAGACCTTCAACACCC-3' and reverse, 5'-AGC ACTGTGTTGGCGTACAGG-3', with amplification length $540 \mathrm{bp}$. The reaction conditions of RT-PCR for PAR-2 used the RT-qPCR kit purchased from Beijing Transgen Biotech Co., Ltd. (Beijing, China), and the reaction included 35 cycles at $94^{\circ} \mathrm{C}$ for $45 \mathrm{sec}, 51^{\circ} \mathrm{C}$ for $45 \mathrm{sec}$ and $75^{\circ} \mathrm{C}$ for $1 \mathrm{~min}$. The reaction conditions for $\beta$-actin were 35 cycles at $94^{\circ} \mathrm{C}$ for $45 \mathrm{sec}$, $55^{\circ} \mathrm{C}$ for $60 \mathrm{sec}$ and $72^{\circ} \mathrm{C}$ for $45 \mathrm{sec}$. The PCR products were separated by $2 \%$ agarose gel electrophoresis and scanned using a GDS 8000 gel documentation system (UVP LLC, Upland, CA, USA). The relative expression of PAR-2 was calculated based on the expression of $\beta$-actin. The experiments were repeated three times.

Western blot analysis. The experimental cells (PAR-2 shRNA-1 EC109 cells, PAR-2 shRNA-2 EC109 cells, nonspecific sequence transfection EC109 cells and EC109 cells) were lysed with RIPA lysate (Beyotime Institute of Biotechnology, Haimen, China) in each group and centrifuged at 3,000 x g and $4^{\circ} \mathrm{C}$ for $10 \mathrm{~min}$ to obtain supernatant. The protein concentration was detected by the bicinchoninic acid method using a BCA kit (Beyotime Institute of Biotechnology). Total proteins $(80 \mu \mathrm{g})$ were loaded onto each well (six wells in total) of $10 \%$ SDS-PAGE and then transferred to polyvinylidene fluoride membranes. The membrane was washed with TBST and blocked with $5 \%$ skimmed milk at $37^{\circ} \mathrm{C}$ for $2 \mathrm{~h}$. The primary antibody (rabbit mAb; cat. no. 6976; Cell Signaling Technology, Inc., Danvers, MA, USA; dilution, 1:1,000) was incubated at $37^{\circ} \mathrm{C}$ for $2 \mathrm{~h}$, followed by incubation at $4^{\circ} \mathrm{C}$ overnight. This was then washed with TBST for 15 min four times. The secondary antibody (goat anti-rabbit; dilution, 1:1,000, Beijing Zhong Shan-Golden Bridge Biological Technology Co., Ltd., Beijing, China) was then added and incubated at $4^{\circ} \mathrm{C}$ for $2 \mathrm{~h}$, and then washed with TBST for $15 \mathrm{~min}$ four times. Finally, the membrane was developed by enhanced chemiluminescence plus reagent (Beijing Dingguo Changshen Biotechnology co., Ltd., Beijing, China). The developed film was scanned and analyzed by Quantity One 4.62 software (Bio-Rad Laboratories, Inc., Hercules, CA, USA). $\beta$-actin was used as an internal control to calculate the relative expression of PAR-2.

MTT assay. In the MTT assay, three groups of EC109 cells were included: Negative control group (transfected with non-specific sequence vector); transfection reagent group (just adding transfection reagents); and PAR-2 shRNA group (PAR-2 downregulated group). The EC109 cells in different 
A PAR-2 ShRNA-1

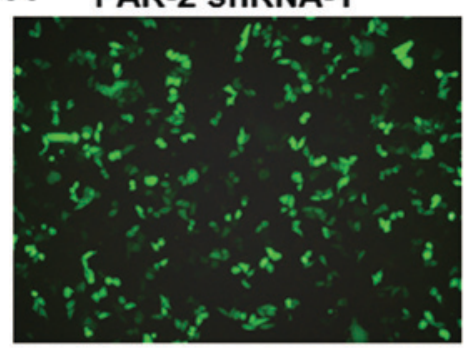

B PAR-2 ShRNA-2

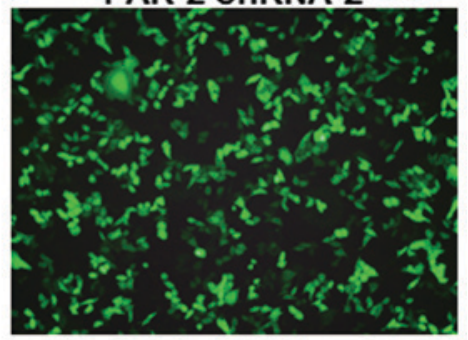

D Blank control

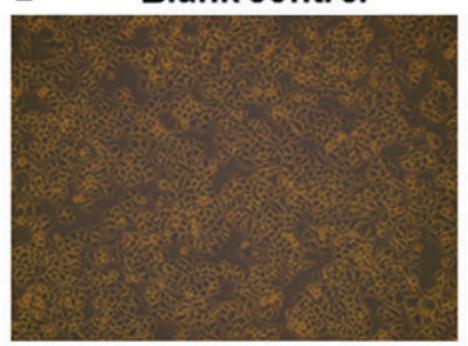

Figure 1. GFP expression in different EC109 cell lines following transfection for $24 \mathrm{~h}$ (magnification, x100). GFP expression in the (A) PAR-2 shRNA-1; (B) PAR-2 shRNA-2; (C) non-specific sequence and (D) blank control groups following transfection for 24 h. GFP, green fluorescent protein; shRNA, small hairpin RNA; PAR-2, protease-activated receptor 2.

groups were cultured in RPMI-1640 medium with 10\% FBS at $37^{\circ} \mathrm{C}$ with $5 \% \mathrm{CO}_{2}$ for $24 \mathrm{~h}$, and the cells in logarithmic growth phase were used for MTT assay. Cells in each group were seeded onto 96 -well plates $\left(2 \times 10^{3}\right.$ per well). The $20 \mu \mathrm{l} \mathrm{MTT}$ solution with $5 \mathrm{mg} / \mathrm{ml}$ concentration was added to each well at 24,48 and $72 \mathrm{~h}$. Following culture for $4 \mathrm{~h}$ at $37^{\circ} \mathrm{C}, 200 \mu \mathrm{l}$ dimethyl sulfoxide was added to end the reaction, The samples were analyzed using an ELISA analyzer (Biomad, Sacremento, CA, USA) and the absorbance of each well was measured at a wavelength of $490 \mathrm{~nm}$. The ratio of inhibited growth was calculated by the formula: Ratio $(\%)=[$ absorbance $(\mathrm{A})$ control-A experiment]/(A control-A blank) x100. The ratio of inhibited growth was used to draw cell growth inhibition curves.

Cell cycle analysis by flow cytometry. The cells in logarithmic phase were seeded into a culture flask at a density of $1 \times 10^{5} / \mathrm{ml}$ for $24 \mathrm{~h}$ at $37^{\circ} \mathrm{C}$ with $5 \% \mathrm{CO}_{2}$. The medium was then replaced with medium without FBS to culture for another $24 \mathrm{~h}$ at $37^{\circ} \mathrm{C}$ with $5 \% \quad \mathrm{CO}_{2}$. The cells were collected by centrifugation $300 \mathrm{x} \mathrm{g}$ for $3 \mathrm{~min}$ at room temperature and washed twice with pre-cooled PBS. The $70 \%$ pre-cooled ethanol was added to fix at $4^{\circ} \mathrm{C}$ overnight. The cells were reserved at $4^{\circ} \mathrm{C}$ and subjected to propidium iodide staining and then the cell cycle was detected using BD flow cytometry (BD Biosciences, San Jose, CA, USA), and data was analyzed using ModFit LT for Windows Version 3.2 (Verity Software House, Topsham, ME, USA).

Transwell migration and Matrigel invasion assays. The migration and invasion assays were performed using Transwell chambers (EMD Millipore, Billerica, MA, USA). Matrigel was thawed at $4^{\circ} \mathrm{C}$ and mixed with serum-free medium with 1:4 ratio as an artificial basement membrane. The Transwell chamber with an $8 \mu \mathrm{m}$ microporous membrane was placed in 24-well culture plates, and the upper chamber was uniformly covered with $40 \mu \mathrm{l}$ artificial basement membrane (BD Matrigel $^{\mathrm{TM}}$ Basement Membrane Matrix; BD Biosciences) mixed with RPMI-1640 at the ratio of $1: 4$. Subsequent to agglutination for 1 at $37^{\circ} \mathrm{C} \mathrm{h}$ in an incubator, the moisture was absorbed from Matrigel to form a matrix barrier.

The cells were seeded into the upper chambers ( $2 \times 10^{5}$ cell/well), while $600 \mu \mathrm{l}$ of medium containing $10 \%$ FBS was added to the bottom of the chamber. Each well had 3 replicates. Following culture at $37^{\circ} \mathrm{C}$ with $5 \% \mathrm{CO}_{2}$ for $28 \mathrm{~h}$, cells were fixed using $10 \%$ formaldehyde at room temperature for $30 \mathrm{~min}$, washed with PBS, and stained with eosin for $5 \mathrm{~min}$ at room temperature. The cells that could not pass through the membrane were wiped. Subsequent to natural drying, the membrane was then dried and moved to the slide and sealed by neutral balsam. Finally, images of the cells were captured under a light microscope (Olympus BX41; Olympus Corporation) with 5 random views. The number of migrated/invaded cells in the bottom chamber was counted and the average of 3 replicates was used. The experimental steps in the migration assay did not include use of Matrigel. The density of cell suspension was $1 \times 10^{5} / \mathrm{ml}$.

Statistical analysis. Data are presented as the mean \pm standard deviation, and were analyzed by SPSS 13.0 software (SPSS, Inc., Chicago, IL, USA). The differences between two groups were determined by Student's t-test. Multi-group analysis was performed by one way analysis of variance, the post hoc test was the least significant difference test. $\mathrm{P}<0.05$ was considered to indicate a statistically significant difference.

\section{Results}

Efficiency of cell transfection. The sequences of the PAR gene in vector were completely consistent with the PAR-2 target 

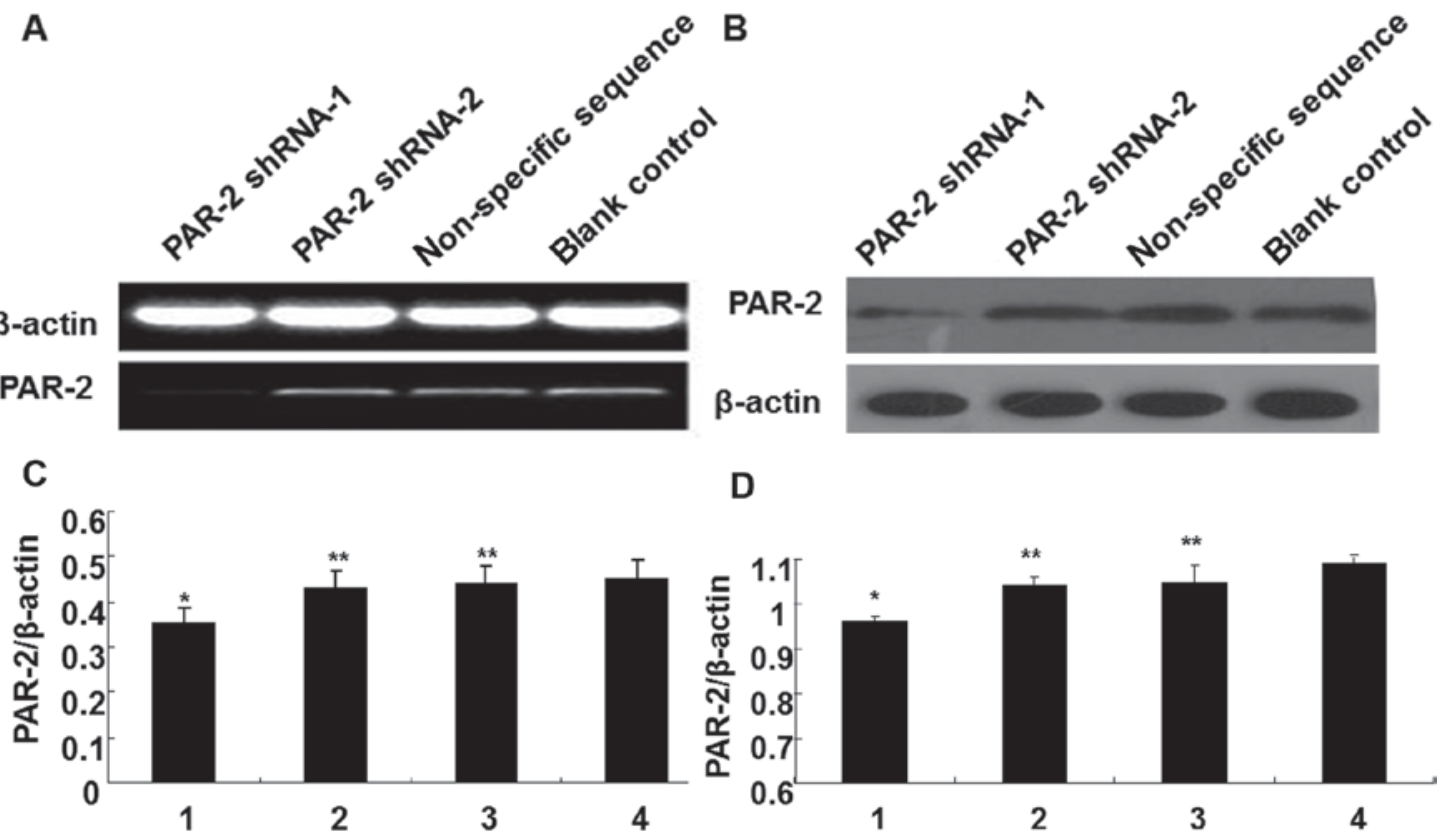

D

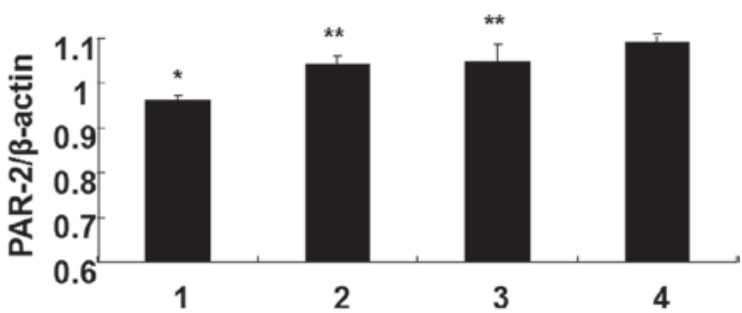

Figure 2. Detection of PAR-2 expression in different EC109 cell lines by RT-PCR and western blot. (A) RT-PCR method to detect mRNA expression of PAR-2 in different EC109 cell lines. (B) Western blot analysis to detect protein expression of PAR-2 in different EC109 cell lines. (C) RT-PCR analysis of PAR-2 mRNA expression levels in EC109 cells following transfection. 1, PAR-2 shRNA-1 group; 2, PAR-2 shRNA-2 group; 3, nonspecific sequence transfection group; 4, control group. (D) Western blot analysis of PAR-2 protein expression levels in EC109 cells following transfection. 1, PAR-2 shRNA-1 group; 2 , PAR-2 shRNA-2 group; 3 , nonspecific sequence transfection group; 4 , control group. ${ }^{*} \mathrm{P}<0.05$ vs. control group, ${ }^{* *} \mathrm{P}>0.05$ vs. control group. RT-PCR, reverse transcription-polymerase chain reaction; PAR-2, protease-activated receptor 2; shRNA, small hairpin RNA.

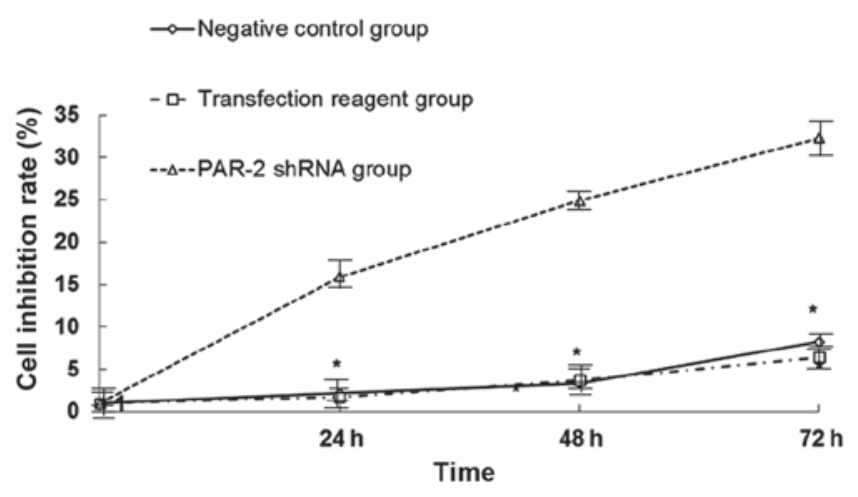

Figure 3. Effect of PAR-2 shRNA on viability of different EC109 cell lines by MTT assay. ${ }^{*} \mathrm{P}<0.05$ vs. PAR- 2 shRNA group. PAR-2, protease-activated receptor 2; shRNA, small hairpin RNA.

sequences. Following transfection for $24 \mathrm{~h}$, the expression of green fluorescence was observed by inverted fluorescence microscopy, as shown in Fig. 1. The transfection efficiency was calculated by the percentage of the number of cells expressing green fluorescence among the total number of cells. The mean transfection efficiency of PAR-2 shRNA-1, PAR-2 shRNA-2 and non-specific sequence group was $67.6 \%$, while no green fluorescence was observed in the blank control group.

PAR-2 expression in different EC109 cell lines by RT-PCR and western blot analysis. To detect PAR-2 mRNA expression following transfection, RT-PCR was applied to different groups. As shown in Fig. 2A, the band intensities were $0.35 \pm 0.03,0.43 \pm 0.04,0.44 \pm 0.04$ and $0.45 \pm 0.41$ in PAR-2
shRNA-1 group, PAR-2 shRNA-2 group, non-specific sequence group and blank control group, respectively. Compared with the other three groups, PAR-2 was significantly downregulated in the PAR-2 shRNA-1 group $(\mathrm{P}<0.05)$. Among the PAR-2 shRNA-2 group, non-specific sequence group and blank control group, PAR-2 mRNA expression had no significant difference $(\mathrm{P}>0.05)$. The results indicated that the constructed PAR-2 shRNA-1 recombinant vector efficiently silenced PAR-2 mRNA.

To detect PAR-2 protein expression subsequent to transfection with recombinant vectors, western blot analysis was performed in different groups. As shown in Fig. 2B, the grey intensities were $0.96 \pm 0.01,1.04 \pm 0.02,1.05 \pm 0.04$ and $1.09 \pm 0.04$ in the PAR-2 shRNA-1, PAR-2 shRNA-2, non-specific sequence and blank control groups, respectively. Compared with the other three groups, PAR-2 was significantly decreased in the PAR-2 shRNA-1 group $(\mathrm{P}<0.05)$. Among the PAR-2 shRNA-2 group, non-specific sequence group and blank control group, PAR-2 protein expression had no significant difference $(\mathrm{P}>0.05)$. The results indicated that the constructed PAR-2 shRNA-1 recombinant vector could efficiently silence PAR-2 expression, which was consistent with PAR-2 mRNA expression.

EC109 cell viability by MTT assay. For studying the effect of PAR-2 on cell viability, a MTT assay was used to detect the changes of proliferation following transfection. As shown in Fig. 3, EC109 cell proliferation in the PAR-2 shRNA group was significantly lower than the negative control group $(\mathrm{P}<0.05)$, and the growth inhibition ratios were 5.92, 24.89 and 32.28\% at 24,48 and $72 \mathrm{~h}$ post-transfection, respectively. Between 

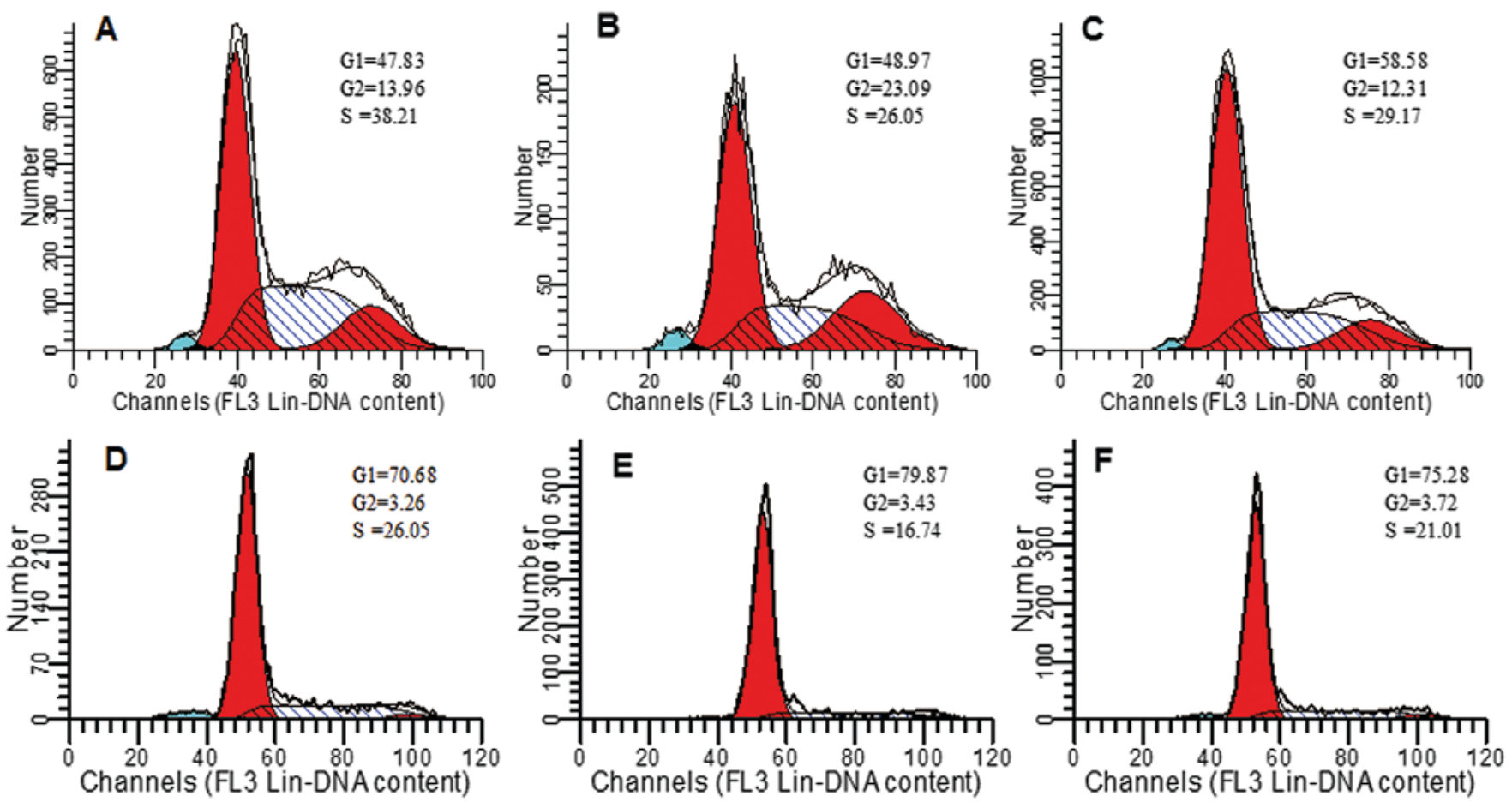

Figure 4. Effect of PAR-2 shRNA on the cell cycle of different EC109 cell lines by flow cytometry. (A) EC109 cell line treated with PAR-2 shRNA for $24 \mathrm{~h}$. (B) EC109 cell line treated with PAR-2 shRNA for 48. (C) EC109 cell line treated with PAR-2 shRNA for $72 \mathrm{~h}$. (D) Control group (without transfection) for $24 \mathrm{~h}$. (E) Control group (without transfection) for $48 \mathrm{~h}$. (F) Control group (without transfection) for $72 \mathrm{~h}$. PAR-2, protease-activated receptor 2; shRNA, small hairpin RNA.

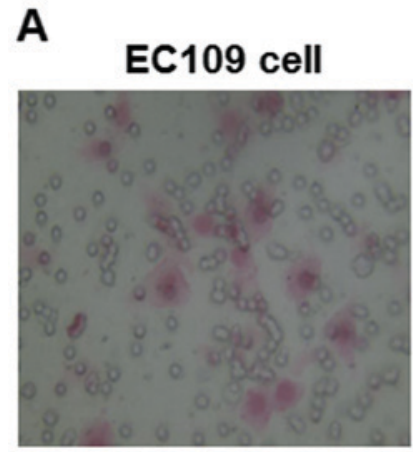

B

EC109 cell

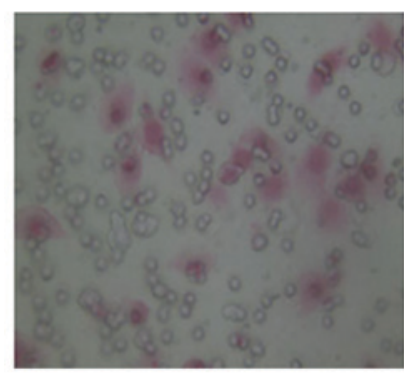

\section{PAR-2 ShRNA}

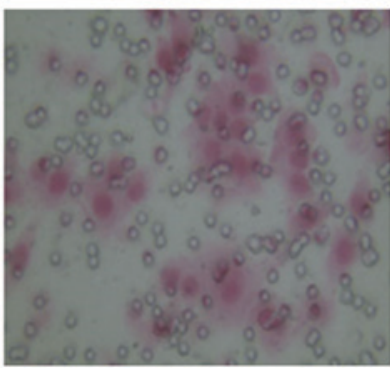

PAR-2 shRNA

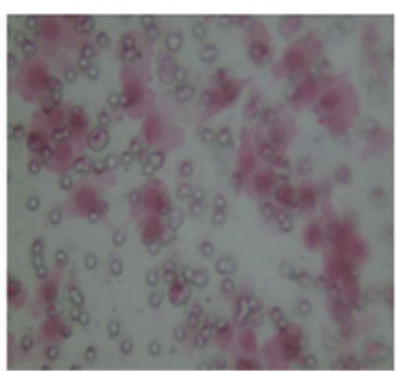

Figure 5. Matrigel and Transwell assays to detect the effect of PAR-2 shRNA on EC109 cell invasion and migration. Cells were stained using hematoxylin and eosin. (A) Cell invasion analysis was measured by Matrigel method on the EC109 cell and PAR-2 shRNA groups (magnification, x200). (B) Cell migration analysis was measured by Transwell method on EC109 cells group and PAR-2 shRNA group (magnification, x200). PAR-2, protease-activated receptor 2; shRNA, small hairpin RNA.

the transfection reagent group and the negative control group, no significant difference was observed $(\mathrm{P}>0.05)$. The results indicated that silenced PAR-2 can repress cellular proliferation in EC109 cell lines, while the transfection reagent and negative plasmid have no significant inhibition roles in EC109 cell viability. 
Table I. Effects of PAR-2 on invasion and migration of silenced and normal EC109 cells.

\begin{tabular}{lll}
\hline \multirow{2}{*}{ Cell number of Transwells } & \multicolumn{2}{c}{ EC109 } \\
\cline { 2 - 3 } & Invasion & Migration \\
\hline Silenced & $19.6 \pm 2.11^{\mathrm{a}}$ & $24.2 \pm 2.82^{\mathrm{a}}$ \\
Control & $30.1 \pm 2.64$ & $43.8 \pm 2.14$
\end{tabular}

${ }^{\mathrm{a}} \mathrm{P}<0.01$ vs. the control group. $(\bar{x} \pm$ standard deviation, $\mathrm{n}=10)$. PAR-2, protease-activated receptor 2 .

PAR-2-induced changes of cell cycle by flow cytometry. To investigate the effect of silenced PAR-2 on cell cycles of EC109 cells, flow cytometry was used to detect the changes of cell cycle. As shown in Fig. 4, S phase arrest was observed in EC109 cells with PAR-2 shRNA transfection. The percentages of cells in the S phase in PAR-2 shRNA-transfected cells and normal cultured cells were $19.37 \pm 2.19,16.93 \pm 2.56$ and $18.74 \pm 2.92 \%$ and $32.79 \pm 4.06,26.54 \pm 1.37$ and $33.45 \pm 2.46 \%$ after 24,48 and $72 \mathrm{~h}$, respectively. The ratio of $\mathrm{S}$ phase cells was significantly lower in EC109 cells transfected with PAR-2 shRNA than in EC109 cells $(\mathrm{P}<0.05)$, which indicated that silenced PAR-2 inhibited cell cycle of EC109 cells.

Effect of PAR-2 shRNA on EC109 cell invasion and migration. To study the changes of EC109 cell behaviors induced by PAR-2 silence, Matrigel and Transwell assays were applied to detect the cell invasion and migration of EC109 cells. As shown in Fig. 5A, numbers of EC109 cells that passed through Matrigel were 19.6 \pm 2.11 and $30.1 \pm 2.64$ in the PAR-2 shRNA and control groups, respectively, and the difference was statistically significant, as presented in Table I $(\mathrm{P}<0.05)$. The results indicated that PAR-2 silence repressed the invasion capability of EC109 cells.

As shown in Fig. 5B, under the microscope (magnification, $\mathrm{x} 200$ ), the number of EC109 cells that moved through the artificial basement membrane by deformation was significantly lower in the PAR-2 shRNA group (24.2 \pm 2.82$)$ compared with the control group $(43.8 \pm 2.14$; Table I, $\mathrm{P}<0.01)$. The results indicated that PAR-2 silence repressed the invasion capability of EC109 cells.

\section{Discussion}

Protease-activated receptors (PARs) belong to a $G$ protein-coupled receptor superfamily with seven transmembrane domains, which includes four subtypes: PAR-1, PAR-2, PAR-3 and PAR-4 (5). All the subtypes contain N-terminus, extracellular loop, seven transmembrane helix, intracellular loop and $\mathrm{C}$-terminal regions (5). The serine cleavage site is hidden in the $\mathrm{N}$-terminus of the PARs, which serves important roles in activated processes (9). In 1994, Nystedt et al (10) identified the DNA sequence of PAR-2 in mice, which was named PAR-2 as it shared a similar structure and activating mechanism to thrombin receptor. PAR-2 is widely expressed in various tissues and organs in the body, and is highly expressed in a variety of gastrointestinal cancer cells, including esophageal, liver, stomach, pancreatic and colon cancers, which are associated with the morbidity, progression and prognosis of tumors $(11,12)$. It was revealed that PAR-2 can be activated by a variety of molecules, including trypsin, human airway trypsin-like protease, sperm acrosin, cathepsin G, tissue factor Xa and activated coagulation factor VIIa and Xa in vivo $(8,13,14)$, and trypsin is one of most effective activators (9). Among tumors in the digestive system, activated PAR-2 can promote invasion and metastasis of tumor cells, regulate tumor cell proliferation, adhesion and angiogenesis $(15,16)$.

RNA interference (RNAi) refers to post-transcriptional silencing processes induced by specific sequences, which can inhibit mRNA expression mediated by small interfering RNA (siRNA) (17). When viral or exogenous genes were randomly integrated into the host genome, double-stranded RNA (dsRNA) was produced, and these dsRNA can be cut into small interfering RNA fragments (siRNAs) 21-23 bp in length by Dicer (18). Under RNA helicase processing, siRNA antisense can form into an RNA-induced silencing complex (RISC) with different enzymes (19). Based on complementary binding, RISC can combine with target mRNA sequences, then the mRNA was cut at position with 12 bp of siRNA $3^{\prime}$ end. The cut mRNA was degraded, which induced post-transcriptional gene silencing (18-20). RNAi is one of most efficient and specific gene silencing mechanisms, which is becoming an effective targeting gene therapy for tumors (21). In the present study, a pGFP-V-RS vector containing PAR-2 shRNA was constructed and transfected into EC109 cells. Following selection by puromycin, stably-transfected EC109 cells were validated by RT-PCR and western blot analysis. PAR-2 was downregulated in mRNA level and protein level, which indicated that recombinant siRNA vector was successfully constructed. It was revealed that activated PAR-2 induces DNA synthesis and cell division (22). MTT assay was applied to detect the proliferation of EC109 cells subsequent to silencing PAR-2. It was revealed that silenced PAR-2 repressed cell proliferation. Through flow cytometry, S phase arrest was observed in PAR-2 silencing cells. Additional studies are required to investigate whether repression of cell proliferation induced by PAR-2 silencing was associated with regulators of the cell cycle.

Besides local proliferation and infiltration, tumor cells will invade to other distant tissues (8). Cell invasion and metastasis in tumors is a complex and continuous process, among which extracellular matrix degradation is a key step (23). Matrix metalloproteinases (MMPs) are a class of $\mathrm{Zn}^{+}$dependent proteolytic enzymes, which can be expressed and secreted in tumor cells and stromal cells, resulting in tumor invasion and metastasis (24). In previous years, it was shown that PAR-2 can promote tumor growth, invasion and metastasis through activation of MMP pathways (24). Through promoting the release of transforming growth factor- $\alpha$, activating epithelial growth factor receptor and kinase extracellular signal-regulated kinase $1 / 2$, PAR-2 can promote cellular proliferation, invasion and metastasis in colorectal and gastric cancers $(24,25)$. Our previous study revealed that PAR-2 can promote invasion and metastasis of HepG2 cells through degrading extracellular matrix by the PAR-2-focal adhesion kinase-MMP-2/9 pathway (8). By RT-PCR, immunohistochemistry and zymography methods, Zhou et al (8) found that PAR-2 receptor 
expressed in EC109 cells, and appropriate concentrations of SLIGKV and trypsin can activate PAR-2 receptor to increase the expression level. Therefore, this promotes cell invasion and metastasis of EC109 cells by promoting MMP-9 secretion and degradation of the extracellular matrix. In the present study, Matrigel and Transwell assays were applied to detect the changes of cell invasion and metastasis of EC109 cells following PAR-2 silencing. It was indicated that the capabilities of cell invasion and metastasis were decreased subsequent to PAR-2 gene silencing. The molecular mechanisms and associated signaling transduction pathways require additional exploration.

In summary, PAR-2 can be downregulated in EC109 cells through RNAi technology. The capabilities of cellular proliferation, invasion and metastasis were decreased following the downregulation of PAR-2 expression. Although it remains unclear whether PAR-2 is involved in repressing the capabilities of cell proliferation, invasion and metastasis in EC109 cells subsequent to gene silencing, PAR-2 target silence by RNAi technology may become a new candidate for treatment in esophageal cancers.

\section{Acknowledgements}

The present study was supported by the Hospital-Level Seed Fund Project of the Affiliated Hospital of Medical School of the Armed Police (grant no. FYM201115).

\section{References}

1. Montgomery EA: Oesophageal cancer. In: World Cancer Report 2014. Stewart BW and Wild CP (eds). IARC, Lyon, 374-382, 2014.

2. Hao J and Shao K: The epidemiology, current status of management, challenge and future strategy for esophageal cancer. Chin Oncol 21: 501-504, 2011.

3. Ciocirlan M, Lapalus MG, Hervieu V, Souquet JC, Napoléon B, Scoazec JY, Lefort C, Saurin JC and Ponchon T: Endoscopic mucosal resection for squamous premalignant and early malignant lesions of the esophagus. Endoscopy 39: 24-29, 2007.

4. Kim T, Grobmyer SR, Smith R, Ben-David K, Ang D, Vogel SB and Hochwald SN: Esophageal cancer-the five year survivors. J Surg Oncol 103: 179-183, 2011.

5. Ossovskaya VS and Bunnett NW: Protease-activated receptors: Contribution to physiology and disease. Physiol Rev 84: 579-621, 2004.

6. Caruso R, Pallone F, Fina D, Gioia V, Peluso I, Caprioli F, Stolfi C, Perfetti A, Spagnoli LG, Palmieri G, et al: Protease-activated receptor-2 activation in gastric cancer cells promotes epidermal growth factor receptor transactivation and proliferation. Am J Pathol 169: 268-278, 2006.

7. Shimamoto R, Sawada T, Uchima Y, Inoue M, Kimura K, Yamashita Y, Yamada N, Nishihara T, Ohira M and Hirakawa K: A role for protease-activated receptor-2 in pancreatic cancer cell proliferation. Int J Oncol 24: 1401-1406, 2004.

8. Zhou J, Xie LQ, Li X, Chen X, Chen L, Zheng Y, Li F: Protease-activated receptor-2 agonists promote cell invasion and metastasis in human esophageal cancer cell line EC109. World Chin J Digestol 13: 1313-1319, 2010 (In Chinese).
9. Macfarlane SR, Seatter MJ, Kanke T, Hunter GD and Plevin R: Proteinase-activated receptors. Pharmacol Rev 53: 245-282, 2001.

10. Nystedt S, Emilsson K, Wahlestedt C and Sundelin J: Molecular cloning of a potential proteinase activated receptor. Proc Natl Acad Sci USA 91: 9208-9212, 1994.

11. Inci K, Edebo A, Olbe L and Casselbrant A: Expression of protease-activated-receptor 2 (PAR-2) in human esophageal mucosa. Scand J Gastroenterol 44: 664-671, 2009.

12. Uchima Y, Sawada T and Hirakawa K: Action of antiproteases on pancreatic cancer cells. JOP 8 (4 Suppl): S479-S487, 2007.

13. Uusitalo-Jarvinen H, Kurokawa T, Mueller BM, Andrade-Gordon P, Friedlander M and Ruf W: Role of protease activated receptor 1 and 2 signaling in hypoxia induced angiogenesis. Arterioscler Thromb Vasc Biol 27: 1456-1462, 2007.

14. Awasthi V, Mandal SK, Papanna V, Rao LV and Pendurthi UR: Modulation of tissue factor VIIa signaling by lipid rafts and caveolae. Arterioscler Thromb Vasc Biol 27: 1447-1455, 2007.

15. Fujimoto D, Hirono Y, Goi T, Katayama K, Hirose K and Yamaguchi A: Expression of protease activated receptor-2 (PAR-2) in gastric cancer. J Surg Oncol 93: 139-144, 2006.

16. Ribeiro FS, Simão TA, Amoêdo ND, Andreollo NA, Lopes LR, Acatauassu R, Rumjanek FD, Albano RM, Pinto LF and Monteiro RQ: Evidence for increased expression of tissue factor and protease-activated receptor-1 in human esophageal cancer. Oncol Rep 21: 1599-1604, 2009.

17. Hannon GJ: RNA interference. Nature 418: 244-251, 2002.

18. Brusselmans K, De Schrijver E, Verhoeven G and Swinnen JV: RNA interference-mediated silencing of the acetyl-CoA-carboxylase-alpha gene induces growth inhibition and apoptosis of prostate cancer cells. Cancer Res 65: 6719-6725, 2005.

19. Filipowicz W: RNAI: The nuts and bolts of the RISC machine. Cell 122: 17-20, 2005

20. Mette MF, Aufsatz W, Kanno T, Daxinger L, Rovina P, Matzke M and Matzke AJ: Analysis of double-strand RNA and small RNAs involved in RNA-mediated transcriptional gene silencing. Methods Mol Biol 309: 61-82, 2005

21. Zhang H, Zheng X, Chen K, et al: SiRNA inhibit the expression of VEGF-C in patients with esophageal carcinoma. Cancer Res Prev Treatment 37: 132-135, 2010 (In Chinese).

22. Zheng YM, Xie LQ, Zhao JY, Li X, Chen XY, Chen L, Hai O and Zhou J: Effects of proteinase activated receptor-2 agonists on proliferation of hepatoma cells. Zhonghua Gan Zang Bing Za Zhi 17: 701-702, 2009 (In Chinese).

23. Zeng ZS, Shu WP, Cohen AM and Guillem JG: Matrix metalloproteinase-7 expression in colorectal cancer liver metastases: Evidence for involvement of MMP-7 activation in human cancer metastases. Clin Cancer Res 8: 144-148, 2002.

24. Caruso R, Pallone F, Fina D, Gioia V, Peluso I, Caprioli F, Stolfi C, Perfetti A, Spagnoli LG, Palmieri G, et al: Protease-activated receptor-2 activation in gastric cancer cells promotes epidermal growth factor receptor trans-activation and proliferation. Am J Pathol 169: 268-278, 2006.

25. Darmoul D, Gratio V, Devaud $H$ and Laburthe $M$ : Protease-activated receptor 2 in colon cancer: Trypsin-induced MAPK phosphorylation and cell proliferation are mediated by epidermal growth factor receptor transactivation. J Biol Chem 279: 20927-20934, 2004. 